\title{
Supraventricular Premature Complex With Unknown Origin by ECG Finding
}

National Cancer Institute

\section{Source}

National Cancer Institute. Supraventricular Premature Complex With Unknown Origin by

ECG Finding. NCI Thesaurus. Code C142246.

An electrocardiographic finding of an ectopic impulse originating from the atria or atrioventricular junction for which the site of orig in cannot be determined from the surface electrocardiog raphic recording; there may be one or more occurrences during an electrocardiographic recording. 